\title{
Envelhecimento Ativo em Questão - Reflexões a partir de uma Oficina de Teatro com Pessoas Idosas
}

\author{
Active Aging in Question - Reflections from a Theater \\ Workshop with Older People \\ Envejecimiento Activo en Questión: Reflexiones de un \\ Taller de Teatro con Personas Mayores
}

Cinthia Lucia de Oliveira Siqueira

João Batista Martins

RESUMO: O conceito de Envelhecimento Ativo, preconizado pela Organização Mundial de Saúde e propagado pelos discursos midiáticos e acadêmicos, carrega certa subjetividade sobre o envelhecer que, a nosso ver, precisa ser reavaliado. Com prescrições sobre o que seria um envelhecimento bem-sucedido, idealiza-se a pessoa idosa-modelo e descarta-se o dissenso e as singularidades. Neste trabalho, apresentamos uma vivência de teatro voltada a pessoas de mais idade, que pretende contribuir com reflexões acerca deste conceito e sugerir formas originais de pensar e viver a velhice.

Palavras-chave: Envelhecimento Ativo; Desenvolvimento humano; Teatro.

ABSTRACT: The concept of Active Aging, advocated by the World Health Organization and propagated by media and academic discourses, carries a certain subjectivity about aging that, in our view, needs to be reevaluated. With prescriptions on what would be a successful aging, idealize the elderly model and discard dissent and singularities. In this paper, we present a theater experience aimed at older people who want to contribute reflections on this concept and suggest original ways of thinking and living old age.

Keywords: Active Aging; Human development; Theater. 
RESUMEN: El concepto de Envejecimiento Activo, defendido por la Organización Mundial de la Salud y propagado por los medios de comunicación y los discursos académicos, conlleva una cierta subjetividad sobre el envejecimiento que, en nuestra opinión, debe ser reevaluada. Con recetas sobre lo que sería un envejecimiento exitoso, idealice el modelo de ancianos y descarte la disidencia y las singularidades. En este artículo, presentamos una experiencia teatral dirigida a personas mayores que desean aportar reflexiones sobre este concepto y sugerir formas originales de pensar y vivir la vejez.

Palabras clave: Envejecimiento Activo; Desarrollo humano; Teatro.

\section{Introdução}

$\mathrm{Na}$ atualidade os termos velhice, envelhecimento, terceira idade, entre outros, são correntes na mídia, nos espaços sociais e nos estudos científicos e, de acordo com diversos autores (Carlos, Jacques, Larratéa, \& Herédia, 1999; Veloz, Schulze, \& Camargo, 1999; Veras, 2001; Neri, 2006; Silva, 2008; Justo, Rozendo, \& Correa, 2010; Debert, 2010; Cordeiro, Pinheiro, \& Correio, 2015; Gonçalves, 2015; Teixeira, Santiago, Cintra, \& Martins, 2015), o aumento da expectativa de vida nos últimos tempos vem alertando profissionais e pesquisadores de distintas áreas.

Segundo o Relatório Mundial sobre Envelhecimento e Saúde (2015), já se registrava, em 2015, 810 milhões de pessoas acima dos 60 anos e, até 2100, a população mundial está prevista em 10,9 bilhões, sendo que mais de 50\% dessas pessoas estarão acima dos 60 anos.

O documento avalia que nenhum país pode se declarar completamente preparado para a "revolução da longevidade", mas que nos países menos desenvolvidos - onde se encontra a maioria das pessoas idosas ${ }^{1}$ do mundo e os determinantes sociais de doença são mais acentuados -, o cuidado com o envelhecimento populacional torna-se um desafio ainda maior.

\footnotetext{
1 A utilização da palavra "idoso" está de acordo com a denominação oficial adotada pelos sensos demográficos, pela Organização Mundial de Saúde (OMS) e pelas políticas sociais que focalizam o envelhecimento, como a Política Nacional do Idoso (PNI) e, sendo assim, refere-se a todas as pessoas que tenham 60 anos de idade ou mais. Partindo deste critério formal e para não privilegiarmos o gênero masculino em nosso escrito, ao nos referirmos a esse grupo, priorizamos a utilização da expressão "pessoas idosas".
} 
Frente a tais evidências observamos o aumento da preocupação com a longevidade e a ampliação dos esforços, no sentido de evitar ou postergar o envelhecer. Isso porque, ainda que o discurso poético sobre a pessoa idosa propale experiência e sabedoria, no ideário social, "o corpo velho remete à antevisão da senilidade, perdas e proximidade da morte. E todos exorcizam o fantasma do seu futuro, afastando-se dele ou até ensaiando destruí-lo" (Motta, 2002, p. 78). Como se a pessoa idosa fosse um ser estranho, com o qual não podemos nos identificar, nem nos reconhecer - "para cada indivíduo, a velhice acarreta uma degradação que ele teme... a atitude espontânea é a de recusá-la, uma vez que se define pela impotência, pela feiura, pela doença” (Beauvoir, 1990, p. 51).

Para trajar o figurino da "nova velhice", busca-se camuflar os apelos do corpo que não consegue frear o tempo. Há um andamento natural inegável que, mais cedo ou mais tarde, atinge a todas/os - cabelo branco, pele flácida, dorso curvo, visão e audição diminuídas, passos vagarosos. Processo que, para quem muito vive, pode tardar, mas não costuma falhar. O fato é que, neste caso, a maioria de nós prefere antes nunca do que tarde - por vezes pronunciamos que preferimos a morte à redenção a uma cama, à dependência, dores. Não queremos as marcas que o espelho denuncia, nem as limitações físicas que nos assombram.

Conforme ressalta Andrews (1999), essa atitude para com a velhice continua florescendo e, enquanto todos os outros estágios da vida são planejados e construídos social e culturalmente, a velhice é colocada à margem, de maneira que não existem conflitos para eliminar a infância, a adolescência e a idade adulta do panorama do desenvolvimento humano, mas da velhice todos tentam escapar - ao mesmo tempo em que as pessoas querem viver muito, não querem ficar (parecer) velhas.

De acordo com Barreto (1992), tal ideia fica evidente em enunciados que elogiam a pessoa idosa por características avessas à longevidade como: velha muito conservada ou velho com espírito jovem, o que demonstra uma necessidade social de negar a velhice tal como ela é, e de valorizar aquilo que ela disfarça.

É o que confirma Correa (2009, p. 27) ao referir que "atualmente, a regra é não envelhecer. Não somente a velhice por si só é indesejável, mas a finitude humana também o é”. A autora ressalta que as pessoas buscam um corpo em que o tempo não atravesse, mas permaneça cristalizado na considerada fase áurea da vida - a juventude. Para ela, os sinais do envelhecimento tornam-se, cada vez mais, humanidades destituídas de valor. 
Acontece que o aumento da longevidade revela algo curioso - ao lado da negação da velhice, a sociedade tem se esforçado por alongar a vida; queremos viver o máximo e envelhecer o mínimo - grande contradição para quem, como Monteiro (2005, p. 57), acredita que "viver é envelhecer e envelhecer é viver... quanto mais vivermos mais velhos estaremos". Igualmente Tótora (2015, p. 47) alega que "só não envelhece quem não está vivo".

Não há como parar o tempo e sempre haverá alguém mais novo que nós... Somos mais velhos desde que nascemos, e envelhecer poderia ser também sinônimo de viver.

No entanto, vários são os autores (Debert, 1999; Neri, \& Freire, 2000; Gusmão, 2001; Zuben, 2003; Papalia, Olds, \& Feldman, 2006; Moreira, \& Nogueira, 2008; Valdès, 2012), que chamam a atenção para o fato de que a sociedade e as próprias pessoas idosas ainda associam a velhice a uma fase sofrida e indesejável, e o que percebemos, a partir destes trabalhos, é que, mais do que aceitar a velhice, tentamos substituí-la pela possibilidade de não envelhecer, e acabamos nos privando do desfrute que as vicissitudes da longevidade podem nos proporcionar.

Ao invés de experimentar uma velhice que aceita sua condição e faz dela matéria prima para uma extraordinária ${ }^{2}$ escultura existencial, somos induzidas/os a dissimular evidências cronológicas, até porque as pessoas idosas que não se enquadram no modelo jovial propagado pela mídia "são responsabilizadas pela má gestão de si mesmas, pelas suas doenças, fracassos, assim como servem de alerta para as demais no controle de suas condutas" (Tótora, 2015, p. 84).

$\mathrm{Na}$ alameda deste fluxo, múltiplos são os serviços e produtos disponíveis à população cada vez mais longeva. Capturadas pelos discursos que exorcizam o envelhecer, as pessoas idosas se rendem aos apelos do mercado e se desgastam em atividades incessantes - vendidas como promessa de manutenção e/ou recuperação da mocidade.

Diferentemente deste ideário, nosso texto busca oferecer outra vista sobre o processo de envelhecimento. Uma abordagem que não disfarce os sofrimentos inerentes às pessoas que envelhecem, mas faça deles potências de existir. Em vez de pautar-nos na compensação do que falta, e almejar o afamado envelhecimento ativo e saudável, sugerimos fomentar as potencialidades da velhice, a partir da liberação das pessoas idosas para o acontecimento vital em sua plenitude - um envelhecer criativo, ou artivo, que assim denominamos para nos

\footnotetext{
${ }^{2}$ Extraordinário é aqui utilizado tanto no sentido de notável como daquilo que escapa ao ordinário e faz-se diferente do costume geral. 
referirmos ao envelhecimento protagonizado por idosas/os artistas - ativas/os e vivas/os entregues à livre invenção de si e do mundo.

Para tanto, iniciamos com uma discussão sobre o aprisionamento da pessoa idosa em novos modelos a serem seguidos, e o consequente aumento da oferta de produtos e serviços que anunciam o postergar da velhice.

Em seguida, questionamos o imperativo do envelhecimento ativo como prescrição quase obrigatória às pessoas que envelhecem. Finalmente, apresentamos a experiência de um idoso participante de uma oficina de teatro, cujas limitações físicas impostas pela idade/doença, transformaram-se em mola propulsora para saídas alegres, criativas e impensáveis de sua existência, contrariando preceitos do envelhecimento bem-sucedido pautados exclusivamente no binômio saúde/doença.

\section{Estetização da vida cotidiana}

A não aceitação do envelhecimento natural, que acontece por parte da maioria das pessoas, tem ocasionado uma crescente estetização da vida cotidiana, quando a imagem se faz soberana e, segundo Featherstone e Werneck (1995), apesar de não termos acesso à fonte da juventude disponível e gratuita, podemos hoje comprar a beleza, o corpo perfeito e até o sucesso e a realização pessoal.

Em meio às transformações pós-modernas, ao mesmo tempo em que se instala uma competição pelo corpo sem marcas de tempo, "existe também um movimento para desconstruir a identidade de velhos de outras gerações e reconstruí-la sob a forma de uma velhice autônoma, ativa e bem-sucedida" (Moreira, \& Nogueira, 2008, p. 6). Incômoda pressão social que atua na negação da velhice tradicional e incentiva a pessoa idosa a combater o envelhecimento físico, psíquico e social.

Como exemplo desta condenação à velhice, o filme americano Cocoon, dirigido por Ron Howard, e estreado em 1985, conta a história de um grupo de pessoas idosas que vivia em sua pacata vida numa casa de repouso, até o dia em que se banham em uma piscina energizada por extraterrestres e passam a sentirem-se rejuvenescidas, com grande disposição e livres de doenças. Para a época, esta narrativa foi uma tentativa de romper com os estereótipos ligados ao determinismo biológico e social associado à velhice e de difundir uma ideia mais otimista e subversiva sobre a mesma. 
Lançado em uma década cuja instituição de direitos e serviços direcionados às pessoas mais velhas ganhava força, seu caráter ficcional coaduna com uma das características marcantes da sociedade contemporânea ocidental - o empenho em flexibilizar as faixas etárias ou, dito de outra forma, descronologizar a vida.

Nesse contexto, juventude e velhice passam a significar valores que podem estar presentes em qualquer idade e, enquanto a primeira deve ser conquistada e mantida, a segunda precisa ser evitada - o rejuvenescer assume sentido de vitalidade, alto astral e cuidados com o corpo, e o envelhecer associa-se a desânimo, depressão, desleixo consigo mesmo.

De acordo com Debert (2010), vivemos um esgarçamento das fronteiras entre as idades confesso em enredos em que mãe e filha partilham das mesmas experiências como namoro, casamento, gravidez, baladas, roupas da moda... O que não deixa de ser uma nova ditadura, uma vez que, "subir um pouco mais nas faixas etárias é ver que a criação da terceira idade foi também acompanhada de um interesse crescente pela imposição da adolescência em outros momentos da vida" (Debert, 2010, p. 55).

Esses apontamentos nos levam a pensar que as pessoas jovens têm cada vez mais dificuldades para aceitar o envelhecer, e as idosas, cada vez mais facilidade para adolescer. Ainda que comportamentos antigamente associados especificamente à juventude ou à velhice se desliguem da idade cronológica, permanecem receitas destinadas a quem, em determinado momento da vida, percebe que precisa adiar ou travar o envelhecimento - como hidratar a pele, adquirir hábitos saudáveis de alimentação, exercitar-se, viajar, vestir-se bem, se inscrever em cursos diversos. Negligente, quem transgredir tais códigos - estará fadada/o ao declínio inevitável do corpo e terá que arcar com as consequências e culpas por sua atitude, ou pela falta dela.

Nas palavras de Tótora (2015, p. 33) "na pretensão de dirigir a vida, controlando o seu processo, com o intuito de melhorá-la (entendendo-se governá-la), multiplicam-se as prescrições a serem seguidas como modelos gerais", ou seja, parece que saltamos de uma universalidade periodizada para uma universalidade sem idade - presas fáceis e ingênuas à disposição do faminto mercado.

A promessa de eterna juventude pode ser antes um mecanismo de constituição de consumidoras/es, uma vez que, "na sociedade de controle, o próprio termo envelhecimento sugere um processo contínuo de estilo de vida saudável e um investimento no corpo desde muito cedo... jovens e velhos estão igualmente sob controle” (Tótora, 2015, pp. 87-88). 
Pessoas idosas ditas bem-sucedidas e que gozam da propagada qualidade de vida, servem de anúncio e influência sobre como devemos ser nas demais faixas etárias, ao passo que as/os longevas/os que escapam a tais modelos permanecem ignoradas/os.

Tal perspectiva merece atenção e cuidado, porque afronta formas originais de existência. A nosso entender, na tentativa de nivelar a conduta das pessoas idosas e prolongar comportamentos ditos juvenis, institui-se perversa tirania de um suposto bem-viver, restando pouco ou nenhum espaço para singularidades ou escolhas.

\section{Envelhecimento Ativo em questão}

Ao lado da preocupação com o aumento da longevidade ganha força o lema do dito "Envelhecimento Ativo" que, segundo o Relatório Mundial sobre Envelhecimento e Saúde (2015), baseado no Programa da Organização Panamericana de Saúde - Organização Mundial de Saúde (OPAS-OMS, 2005, p. 45) "pode ser definido de acordo com a atual perspectiva teórica de resiliência - ter acesso às reservas necessárias a se adaptar, suportar e aprender com os desafios enfrentados ao longo da vida".

O documento refere que as metas do Envelhecimento Ativo são preventivas, restaurativas e paliativas e visam ao bem-estar e à qualidade de vida da pessoa idosa, sendo que a proposta não se restringe à atividade física ou à participação na força de trabalho, mas abarca também o engajamento significativo na vida social, cultural, espiritual e familiar, bem como no voluntariado e em causas cívicas.

O texto cita como, componentes fundamentais para o Envelhecimento Ativo, a saúde, a participação, a segurança e a aprendizagem ao longo da vida - tidos como "recursos ou tipos de 'capital' que, quando acumulados ao longo do curso de vida, passam a ser os fundamentos para o bem-estar físico, mental e social em todas as idades" (OPAS-OMS, 2005, p. 44). E complementa que "quanto mais cedo esse acúmulo dos capitais vitais de saúde, geração de renda, redes sociais e conhecimento começar, melhor" (OPAS-OMS, 2005, p. 44).

Segue mencionando a saúde (física e mental) como o requisito essencial para a qualidade de vida. A participação é vista como pré-requisito para o gozo da boa saúde e a aprendizagem, enquanto recurso renovável essencial para que uma pessoa se mantenha saudável, atualize conhecimentos e habilidades e garanta sua segurança pessoal - "quanto 
mais saudável e instruído se é, em qualquer idade, maiores as chances de se participar plenamente na sociedade" (OPAS-OMS, 2005, p. 44).

Compreendemos que tais afirmações implicam em desdobramentos que normatizam ações e serviços oferecidos a pessoas idosas - em nível governamental e privado. Diante disso, o modelo que preconiza saúde e instrução, apesar de bem-intencionado, prescreve um envelhecimento idealizado.

Para Tótora (2017), o conceito de Envelhecimento Ativo tem mobilizado a forma de pensar a velhice tanto no campo acadêmico quanto midiático. A autora, que destaca significativas mudanças de abordagem no Programa do Envelhecimento, especialmente a colocação do tema na agenda política, faz um alerta à minoria das pessoas idosas que, por deixarem de satisfazer a um ou outro requisito indicado, são colocadas fora do sistema.

Da maneira semelhante, Belo (2013) comenta que a tendência de induzir uma nova imagem de velhice associada ao conceito de Envelhecimento Ativo, o qual compreende as ideias de produtividade, alegria e melhor idade, necessita ser observada criticamente, como forma de não seguir a tendência de homogeneizar as pessoas idosas e de se evitar, portanto, "o deslocamento de uma concepção sobre velhice baseada no estereótipo de improdutividade ou doença, para outra imagem, que igualmente homogeneíza, embora em outro extremo, como sinônimo de vitalidade e saúde" (Belo, 2013, p. 16) ao que Ana Amélia Camarano, durante o Fórum Nacional da Mulher Idosa (FNMI) reforça: “eu acho que é um perigo a gente fazer generalização sobre essa fase da vida... seja de uma perspectiva negativa ou de uma perspectiva ativa, qualquer que seja a generalização, ela pode ser perigosa" (FNMI, 2012, p. 32).

Para as estudiosas acima, a defesa acrítica do conceito de Envelhecimento Ativo pode camuflar problemas sentidos por grande parte das pessoas que envelhecem e gerar efeitos contraditórios, pois "se por um lado estimula a autoestima e a capacidade das pessoas idosas, contribuindo para desconstruir os estereótipos anteriores associados à ideia de incapacidade e doença, por outro, cria a responsabilidade e a obrigação por parte deste grupo social de buscar sua sobrevivência" (Belo, 2013, p. 16).

Tótora (2015) pondera que esse discurso sobre a velhice ativa e bem-sucedida, que povoa os meios de comunicação e grande parte da academia, é intolerável, porque circunscreve um controle e monitoramento - uma imposição, quase obrigação, depositada na pessoa idosa, que passa a carregar a culpa por possíveis malefícios vividos - "a ciência e o Estado, com sua promessa de bem-estar, segurança e felicidade, não somente extraem sua 
força de agir, como também proclamam outro mundo, distinto da história e da vida" (Tótora, 2015, p. 24). Como se fosse proibido ficar velha(o), dito de outra forma, como se fosse possível não envelhecer. Nestes termos, ela entende que o dito Envelhecimento Ativo pretende, acima de tudo, estagnar a velhice.

De acordo com a autora, seguindo a lógica da prevenção e do consumo aos produtos ofertados pelo mercado da saúde, a senha para um discurso ser aceito é a defesa de um envelhecimento com qualidade de vida. "Esse gozo subentende uma saúde normalizada por padrões estatísticos e monitorada individualmente por agentes da saúde do Estado e por empresas de seguro privadas" (Tótora, 2015, p. 12) e "saúde a qualquer custo significa eliminar os riscos de envelhecer" (p. 47).

Na contramão dessa hegemonia discursiva, Tótora (2017) recomenda a velhice como acontecimento, invenção e resistência - um esgotar da vida, que não se restringe ao bem-estar, mas à disposição de enfrentar as adversidades e delas construir potências de agir - novas formas de existência. Ao questionar o "Envelhecimento Ativo" como a palavra de ordem do novo milênio sugere que seja substituída por "envelhecimento artista" - enquanto percurso singular de cada sujeito que envelhece - "longe, portanto, de qualquer modelo" (Tótora, 2017, p. 253).

Segundo Tótora (2015), uma operação artística de viver relaciona-se à estética da existência - à possibilidade de fazer de nossa vida uma obra de Arte no sentido de nos constituirmos a cada momento, de nos transformarmos, de fazermos de nossa relação conosco uma atividade criativa. A Arte, para Tótora (2015), configura-se enquanto um modo singular de subjetividade, uma resistência poética aos discursos produzidos na atualidade sobre velhice e envelhecimento. Para a autora, ser artista é poder experimentar nuances de vida impulsionadas pela tonalidade dos afetos, os quais escapam a todo e qualquer controle e/ou previsão e permitem a construção do inédito.

Seria um envelhecer que não se deixa capturar em programas ${ }^{3}$ propagados pelo governo e que carregam consenso e preceitos gerais sobre o que se espera da pessoa idosa, no caso, um envelhecimento com saúde, segurança e participação, restando "pouco ou quase nenhum espaço para o dissenso, as singularidades e as diferenças - no sentido de uma individuação que transvalora os valores difundidos" (Tótora, 2017, p. 242).

\footnotetext{
${ }^{3}$ A autora refere-se aqui ao movimento global pelo envelhecimento ativo lançado no Dia Internacional da Saúde e Ano Internacional do Idoso, 1999. Tal movimento é retomado no programa da Organização Mundial de Saúde - OPAS-OMS (2005) e seus desdobramentos estão registrados no Relatório Mundial de Envelhecimento e Saúde publicado no ano de 2015.
} 
O que ela vislumbra é uma possibilidade de criar formas de existir diversas - que não neguem a condição da velhice, mas a liberem para o infinito da vida - em eterno devir. Ora, diria Tótora (2015, p. 64), "não seria a velhice o momento privilegiado para simplesmente 'ser' livre dos códigos e modelos que aprisionam os viventes na sociedade?’. Para ela, a velhice poderia constituir-se em meta positiva da existência e, ao invés de nos resignarmos e ter que, um dia, enfrentá-la, deveríamos tender a ela. Aconselha que deixemos de lado a ideia de velhice como castigo ou prêmio: "é preciso pensar fora desta lógica de punição e recompensa por um tipo de existência" (Tótora, 2015, p. 101).

Concordando com a perspectiva da autora, compreendemos que a existência é sempre obra de arte inacabada e, portanto, a reinvenção de nós mesmos fora de qualquer concepção pré-estabelecida; nesse sentido, acreditamos que os serviços oferecidos às pessoas idosas devem ter em vista a livre e inusitada criação, no lugar de deliberada e prevista prescrição.

Ao invés de nos atermos a palavras de ordem do afamado Envelhecimento Ativo, propomos vivências que liberem a pessoa idosa para sua constituição singular, para a experimentação do imprevisível e, para tanto, consideramos o teatro como um valioso instrumento.

\section{Linguagem teatral e criatividade na velhice}

A nosso ver, a linguagem teatral se faz privilegiada no sentido de transgredir os códigos existentes na sociedade, porque, como aponta Cordeiro (2015) ${ }^{4}$, os participantes podem "enxergarem-se como sujeitos, como agentes e produtores de cultura, capazes de atuar num palco, de criarem textos e peças teatrais, de perceberem que a própria forma da sociedade encarar a velhice depende de contextos históricos e é passível de modificação" (Cordeiro, 2015, p. 74).

Relevante acentuar que, em diversos artigos visitados (Barros, \& Búrigo, 2005; Braga, Horioka, \& Ferreira, 2010; Campos, Santos, Moura, Aquino, \& Monteiro, 2012; Laroque, Affeldt, Gheno, Dias, \& Santana, 2013; Souza, \& Wechsler, 2013; Pavón, \& Dottori (2015), percebemos certa tendência acadêmica em se associar as atividades de Arte na longevidade à possibilidade de melhorar a qualidade de vida e o bem-estar da pessoa idosa.

\footnotetext{
${ }^{4}$ Cordeiro é coordenadora da oficina de teatro da Universidade Aberta da Terceira Idade, na Unesp de Marília, SP, desde 1999. 
Não negligenciamos estes benefícios, mas eles não são nosso objetivo de intervenção, nem nosso foco de estudo. Isso porque, a nosso ver, há um sutil desmerecimento do envelhecer quando se entende que toda a atividade voltada à pessoa idosa precisa salvaguardá-la de suas desventuras. Entendemos que a Arte na velhice não precisa necessariamente ser sinônimo de tratamento, lazer ou descontração - não poderia ser tratada como beneficência aos que são significados como carentes de vida e alegria.

Como aponta Miguel (2012), no trabalho com arte-educação, frequentemente se observam os extremos: ou a arte pela arte, dotada de técnica e comprometida apenas com a qualidade artística, ou "o arte-educador que não se compromete com a qualidade, nem com a técnica, acreditando que o teatrinho está muito bom e que os idosos não conseguiriam fazer além do que já demonstram nos jogos, e que por estarem ali se distraindo já estão promovendo a saúde" (Miguel, 2012, p. 14).

Nosso posicionamento é que se deve buscar a estética do fazer artístico, no sentido do poético, do simbólico - porque é esta a dimensão capaz de promover o diálogo profícuo entre a atriz/ator idosa/o e seu público, contribuindo para desmistificar os mitos negativos associados ao envelhecimento e acarretando significativas mudanças sociais, históricas e culturais na velhice, na sociedade e na própria arte dramática. Através do teatro, acreditamos que a pessoa idosa possa mergulhar em sua verdade absoluta, "sem racionalizar o certo ou errado, divertindo-se como alguém que experimenta o novo, e goza do prazer de sentir-se livre dos pré-conceitos sociais que limitam seu poder criativo" (Miguel, 2012, p. 15).

Dessa forma, procuramos cuidar para não vincularmos o fazer artístico à promoção de saúde e/ou à prevenção de doenças; também abdicamos de ideias como resgate da cidadania, da autoestima e reinserção social, pois não significamos a velhice em desvantagem. No lugar da melhora dos aspectos cognitivos, escolhemos pensar na complexificação da relação entre linguagem e pensamento, porque não partimos das perdas conferidas às/aos longevas/os, mas das potencialidades de um sujeito em infindável constituição. Para nós, a pessoa idosa, como todo o ser, está em devir, e não pode ser apartada do fluxo contínuo de nossa existência. Tem suas especificidades, que não lhe conferem lugar menor, mas distinto e, portanto, singular.

Defendemos que as pessoas mais velhas se beneficiam do fazer criativo, porém, não somente elas, e sim, todas/os nós. No lugar de declarar que o teatro acrescenta qualidade de vida à pessoa idosa, preferimos ressaltar que a pessoa idosa acrescenta qualidade estética ao 
teatro, uma vez que os gestos e a voz do corpo envelhecido inauguram linguagens e símbolos que outros corpos não conseguiriam fazê-lo.

Nesse sentido, destacamos a revisão de literatura realizada por Bernard e Rickett (2017), a respeito do valor da participação de pessoas idosas no teatro. A pesquisa compreendeu artigos de língua inglesa (em especial do Reino Unido e dos Estados Unidos), publicados entre os anos de 1979 e 2015. As autoras observaram que a maioria dos artigos versava sobre a relação entre a arte dramática e a saúde, o bem-estar e os relacionamentos de grupo. Uma quantidade menor dos trabalhos tematizava o aprendizado e a criatividade e um número quase inexpressivo sinalizava a importância do valor estético e da qualidade do drama das pessoas mais velhas.

Para Bernard e Rickett (2017), a falta de atenção ao valor estético do teatro sênior chama a atenção para a necessidade de melhorar a nossa compreensão acerca do valor cultural fornecido por pessoas mais velhas, ao invés de apenas ressaltarmos o valor que o teatro representa a elas. Acreditamos ser este um aspecto importante a se pensar, porque desloca a pessoa idosa da ausência de vitalidade para a abundância de recursos - do lugar de quem necessita de compreensão e auxílio, para o lugar de quem contribui com as transformações sociais e, ao fazê-lo, promove a mudança de si e de outras pessoas.

É o que demonstra o estudo de Silva, Vianna e Bezerra (2013) que, ao analisarem os autorretratos de Rembrandt, salientam que as melhores pinturas foram as produzidas no fim de sua vida. Em suas análises, chamam a atenção para outros $\operatorname{artistas}^{5}$ renomados, que expressaram na velhice estilos refinados e sofisticados, e concluem que "a constatação de um estilo tardio, com todas as suas polêmicas ou incongruências, vem dar força à possibilidade de ser possível começar ou recomeçar na velhice, reforçar ou redirecionar a atividade criativa" (Silva, Vianna, \& Bezerra, 2013, p. 86), pois com a idade, "alguns artistas tornam-se mais conservadores, enquanto outros adquirem espírito mais livre e tolerante, tornando-se progressistas" (p. 86).

Ressaltamos também trabalhos como os de Bezerra, Baldin e Justo (2015) que desenvolveram oficinas de fotografia e teatro junto a idosas, com o objetivo de colocá-las em prospecção, enquanto mulheres desejantes e autoras da própria história - protagonistas de seus desígnios. Relatam os autores que as encenações que as pessoas idosas criaram nas oficinas expressaram "a narrativa de si e do seu devir, interligando presente e futuro, com isso,

\footnotetext{
${ }^{5}$ Como Cézanne, Goya, Michelangelo, Sófocles, Eurípedes, Tolstoy, Goethe, Cervantes, Ibsen, Beckett, Beethoven, Britten, Verdi, Wagner, Schoenberg, Strauss, Galileu e Kant.
} 
tornando as limitações impostas por kronos insignificantes, diante da magnitude da existência vivida como Kairós" (Bezerra, Baldin, \& Justo, 2015, p. 251). Experiência que nos remete à concepção de Arte como instrumento de bricolagem (tanto de nosso universo interno quanto externo), exercício que não estagna com o tempo, tampouco perde seu valor, porque há materiais envelhecidos tão raros quanto caros - que enriquecem a multiplicidade do ser e do universo que o circunda.

Corroborando esta linha de pensamento, finalizamos com um apontamento de Vigotski (1930/2009) ${ }^{6}$ sobre imaginação e criação. Para o autor, os elementos utilizados na construção teatral são absorvidos da realidade em que os sujeitos estão inseridos e depois submetidos a uma complexa reelaboração interna, até transformarem-se em produtos da imaginação - "finalmente, ao se encarnarem, retornam à realidade, mas já como uma nova força ativa que a modifica. Assim é o circulo completo da atividade criativa da imaginação". (Vygotski, 1930/2009: 30).

E foi com esta convicção - a de que a atividade criadora é a essência de nosso processo de transformação e, portanto, de humanização - que, em 2014, iniciei minha atividade de professora de literatura e teatro em uma Universidade Aberta da Terceira Idade (UATI). ${ }^{7}$

\section{Metodologia}

O convite para este trabalho veio da coordenadora do referido programa, que soube, por intermédio de outra coordenadora (do curso de pedagogia onde eu lecionava), de minha ${ }^{8}$ paixão e afinidade com a palavra e com a arte dramática.

Por estar imersa no trabalho com arte dramática da UATI, no segundo semestre de 2018, recebi outro chamado de um centro cultural (mantido por indústria local), para o desenvolvimento de uma oficina de teatro voltada a pessoas idosas.

\footnotetext{
${ }^{6}$ Nesta notação bibliográfica, o ano inicial se refere à escrita do texto original e o segundo, à publicação do texto em espanhol consultado para esta pesquisa.

${ }^{7}$ Relato da autora 1 desta investigação (orientada pelo autor 2), que, a partir deste ponto do artigo, assume a primeira pessoa verbal ao explicitar a metodologia.

${ }^{8}$ Importante contar que, desde 2010, desenvolvo oficinas de formação de professores e alunos no âmbito da narrativa oral, escrita criativa e teatro do espontâneo. Graduada em fonoaudiologia, meus estudos e atuação profissionais sempre estiveram atrelados à linguagem, ao desenvolvimento humano e, recentemente, aos processos de envelhecimento. Esta fora a temática de meu doutorado e hoje faz parte de meu maior deleite em pesquisa, formação e atuação.
} 
A proposta era que eu trabalhasse com o grupo durante sete semanas e, ao final, apresentasse um espetáculo teatral a um público externo. Ao lado da tentação, o desafio era temeroso - construir uma performance em tão breve período de tempo, junto a um grupo que eu ainda desconhecia. Aceitei! E as interações e ponderações que emergiram desta fugaz vivência fizeram parte de minha pesquisa de doutorado, que já se encontrava em andamento.

A linha metodológica por nós adotada fora a pesquisa participante de cunho qualitativo e o instrumento de coleta de dados, o diário de campo. Após cada encontro, fazíamos a rememoração daquilo que ficava, porque a nós significava.

O grupo de vivência denominado melhor idade ${ }^{9}$ é perene, mas as/os participantes têm a liberdade de se inscreverem ou não em cada módulo mensal. Ao final, se tiverem presença suficiente, recebem certificado de conclusão.

Qualquer pessoa com mais de 50 anos pode fazer inscrição nas atividades que são gratuitas e abertas à população. A divulgação das atividades fica a cargo do próprio centro cultural e é realizada por meio de mídia impressa e digital, como jornais, redes sociais, entre outras.

O grupo tem atividades diversas que acontecem uma vez na semana. em horário prédeterminado. A cada mês há uma atividade específica. São convidados professores de várias áreas para integrar a programação anual. No ano em que fui chamada, já haviam tido a atividade de arte sacra, músicas brasileiras e oficina de memória. O teatro encerraria o primeiro semestre de 2018.

Ao todo foram 32 participantes - 03 homens e 29 mulheres, com idades que variavam entre 65 e 89 anos. Os encontros duravam 1h30min e aconteceram durante os meses ${ }^{10}$ de maio e junho de 2018 com periodicidade semanal. Como tínhamos poucos ensaios e o compromisso de uma apresentação ao final do processo, escolhi trabalhar com os fundamentos da mímica teatral que dispensa a memorização de texto e permite maior improviso.

A oficina foi estruturada de maneira que contemplássemos uma técnica por dia, seguida da constituição de uma narrativa teatral, criada pelas/os próprias/os participantes.

Privilegiamos o exercício do espontâneo e da livre criação, onde o lúdico fora protagonista, porque, como ressalta Cordeiro (2006, p. 69), “o lúdico é o elemento de prazer que perpassa os atos de criação humana, os jogos, a representação, a própria cultura”.

\footnotetext{
${ }^{9}$ Esse é o termo utilizado pelo centro cultural e acatado pelas(os) idosas(os) participantes da oficina.

${ }^{10}$ A maioria das atividades acontece em apenas um mês. Para o teatro, aceitaram minha solicitação de expansão para dois meses.
} 
A partir dos apontamentos de Martins (1996), sobre a observação participante, acreditamos que nossa convivência com o grupo estudado criou condições privilegiadas para que o processo de observação fosse conduzido e desse acesso a uma compreensão que de outro modo não seria alcançável, isso porque, ao participarmos das vivências, nos fizemos implicados na pesquisa e, desta condição, insurgiram afetos fortes o bastante que merecem ser narrados.

Vale dizer que a pesquisa foi submetida ao Comitê de Ética e Pesquisa (CEP) de uma Universidade do Estado de São Paulo e aprovada sob o número 1.870.288; dessa forma, o estudo se fez com o conhecimento e o consentimento escrito de cada uma das participantes, estando livres de riscos, desconfortos físicos, emocionais ou morais, imediatos ou tardios.

Para este artigo, apresentaremos uma situação em especial, pois ela bem representa o que desejamos aqui expressar - o potencial inventivo da pessoa idosa fora de qualquer tentativa de determinação - seja ela biológica, histórica, social ou cultural.

Elegemos o caso do Sr. Manoel ${ }^{11}$, porque carregado de sentido a respeito das relações entre doença e saúde, envelhecimento e potência de vida. Passemos a ele...

\section{A vivência do Sr. Manoel}

Manoel tinha na época 88 anos de idade e estava em tratamento quimioterápico em virtude de um câncer de pele em estágio avançado, o qual acometeu, dentre outras regiões, todo o seu rosto. Por esse motivo, a expressão facial de Manoel possuía limitadas possibilidades de movimentação. Apesar desta e de outras restrições físicas, não se recusou a nenhuma das vivências; ao contrário, empenhou-se em todas elas.

Houve um momento específico em que trabalhamos máscaras faciais. Antes de apresentar a proposta ao grupo, antecipei, em pensamento, uma possível resistência e/ou dificuldade por parte de Manoel, imaginando que ele não participaria neste dia - o que quase fez com que eu eliminasse a dinâmica de meu planejamento. Arrisquei mantê-la e, para a desconstrução de meu pré-conceito, ele não demonstrou qualquer rejeição em lançar-se à atividade e, no esforço de movimentar a musculatura facial, construiu expressões surpreendentes, porque singulares e destacadas das/os colegas idosas/os.

\footnotetext{
${ }^{11}$ Nome fictício.
} 
Enquanto a maioria empenhou-se em produzir caras e bocas cômicas, porém estereotipadas, Manoel dispendeu laborioso trabalho de contração muscular, tanto quanto possível. Ao fazê-lo, fugiu da expressão cristalizada e alcançou o inusitado - o artístico, no sentido de novos possíveis, "rompendo as cadeias de uma dada identidade, hábito ou subjetividade" (Tótora, 2015, p. 27). Ao desviar-se da máscara usual, enveredou-se em uma operação artística de viver, distinta do saber ou do poder, distante de códigos estabelecidos.

Evidente que Manoel não o fez deliberadamente, com a intenção do excepcional - este foi consequência do esforço físico, da experimentação do corpo transformado pela doença - o que, a nosso ver, por si só, constitui contravenção aos discursos de envelhecimento saudável. Quando aceitou brincar com a mímica facial, ele ampliou suas possibilidades criativas, ultrapassou os limites do óbvio - deslizou sobre o problema, sofrimento, dor e doença (Tótora, 2015).

Contradizendo a representação de que a saúde se sobressai à enfermidade, na atividade de expressão facial, o limite físico revelou uma nova possibilidade de existir - potência de vida. Não estamos com isso exaltando a doença, que sabemos penosa, mas considerando que enfrentar as adversidades, ao invés de apenas evitá-las, é também abrir-se à vida - criar-se, "constituir-se a si mesmo a cada momento, saber se transformar, produzir-se, modificar-se, em suma, fazer da relação consigo mesmo uma relação criativa” (Foucault, 1995, p. 262).

Vida artista, segundo Foucault, é inventar-se fora de qualquer concepção preexistente. E o que se esperaria de Manoel senão uma dificuldade em realizar a atividade? Ao contrário de frágil, ele deixou-se atravessar por sua força vital - experimentou um envelhecimento artivo - como o artista que livremente arquiteta sua casa interna e externa.

No dia da apresentação final, combinamos de fazer a maquiagem juntos no centro cultural. Manoel, aliado a outras mulheres, escolheu pela primeira vez passar batom - queria realçar a expressão de seus lábios; queria potencializar-se, ser artista de sua própria vida - "e ser artista da própria vida é tornar as coisas belas, até mesmo as mais ínfimas banalidades do cotidiano" (Nietzsche, 1996, p. 299).

\section{Considerações finais}

O desafio oferecido a Manoel representou uma situação de conflito entre as possibilidades do corpo e as exigências físicas do exercício, a que ele buscou superar, deslocando-se do lugar de sujeito do não para o de sujeito do sim. E dizer sim à vida exige a 
força e a audácia de dizer não a certos impedimentos. Enquanto na fisionomia habitual de Manoel observavam-se reduzidas nuances expressivas, no exercício teatral a singularidade de seus gestos faciais sobressaíra de si e dos outros.

Acreditamos que a constituição grupal contribuiu para esse sobressalto, porque ofereceu o "espelho" da velhice - estampada em cada corpo envelhecido. Posicionadas(os) todas(os) diante de um evento dramático, em que necessitaram contrariar o biológico, elas(es) se instigaram, brigaram com os limites - próprios e da(o) outra(o).

Tal evento nos proporcionou a compreensão de que os grupos de pessoas idosas constituem-se espaços privilegiados de transformação interna, não porque substituem isolamento por atividade, mas porque pode inseri-las na arena da disputa (com outras pessoas e consigo mesmo) - deslocando-as e atribuindo novos sentidos às suas experiências.

Em oposição aos discursos sobre envelhecimento saudável, ativo e produtivo, defendemos que uma existência que quer impedir a morte e a doença é uma existência fraca; afinal, "experimentamos em nossa existência múltiplas mortes para potencializar a vida. Estancar o processo de envelhecimento é o mesmo que paralisar a vida" (Tótora, 2015, p. 48). Como nos diz a autora, potencializamos nossa força vencendo resistências e "viver o acontecimento é lançar-se ao infinito dos possíveis que se abrem, rompendo as cadeias de uma dada identidade, hábito ou subjetividade" (p. 27).

Nas atividades desenvolvidas durante as aulas de teatro do centro cultural, as/os idosas/os muitas vezes foram compelidas(os) a arriscarem-se em atividades ainda não experimentadas, a entrarem em contato com o mundo do desconhecido e a colocarem-se em devir, porque as novas experiências traziam a necessidade de se criarem outras formas de agir e pensar - elas/es sentiam que era preciso sair do lugar, buscar um outro sentido à nova realidade que se apresentava. E a partir do momento em que tomam consciência deste movimento, deste novo campo de possibilidades, se recolocam, se transformam.

No lugar de uma vivência que preconiza saúde e instrução, recomendamos que é preciso liberar as pessoas idosas das mesmices e opressões propagadas - abdicar da tutela, da monitoria de suas vidas, para potencializá-las, a fim de que possam se emancipar do conhecimento e das tecnologias criadas para gerir suas vidas. Pensamos que a situação analisada corrobora a ideia de que é urgente resistir às preleções produzidas na atualidade sobre a velhice e deixar fluir a vida para modos singulares de existência. 
E foi isso que Manoel nos apresentou: fez da relação consigo mesmo - com seu corpo debilitado e envelhecido, uma atividade criativa - recriou-se como obra de arte, surpreendendo e contrariando qualquer previsão. Ao expressar a verdade de sua máscara facial experimentou a singularidade que sua condição física lhe oferecia, inaugurou um mundo de possíveis e rompeu o restrito espaço que o cotidiano, muitas vezes, insiste em reservar às pessoas que envelhecem.

\section{Referências}

Andrews, M. (1999). The seductiveness of agelessness. Ageing and Society, 19(3), 301-318. Recuperado em 08 julho, 2019, de: https://www.cambridge.org/core/journals/ageing-andsociety/article/the-seductiveness-of-agelessness/06E47CD7FD416F313A9BF588A7957285.

Barreto, M. L. (1992). Admirável mundo velho: velhice, fantasia e realidade social. São Paulo, SP: Ática.

Barros, M. A., \& Búrigo, S. (2005). Oficinas pedagógicas no exercício da criatividade e educação permanente na velhice. Estudos Interdisciplinares do envelhecimento, 7, 117-134. Recuperado em 08 junho, 2019, de: https://seer.ufrgs.br/RevEnvelhecer/article/view/4761.

Beauvoir, S. de. (1990). A velhice. Rio de Janeiro, RJ: Nova Fronteira.

Belo, I. (2013). Velhice e mulher: vulnerabilidades e conquistas. Revista feminismos, 1(3), 1-20. Recuperado em 08 julho, 2019, de: https://portalseer.ufba.br/index.php/feminismos/article/view/ $29997 / 17739$.

Bernard, M., \& Rickett, M. (2017). The cultural value of older people's experiences of theater-making: a review. The Gerontologist, 57(2), 1-26. Recuperado em 08 julho, 2019, de: https://doi.org/10.1093/geront/gnw093.

Bezerra, P. V., Baldin, T., \& Justo, J. S. (2015). Oficinas de Psicologia com idosos e as possibilidades de ressignificações do presente e futuro. Revista Kairós-Gerontologia, 18(3), 433-455. Recuperado em 08 julho, 2019, de: https://revistas.pucsp.br/index.php/kairos/article/view/29333.

Braga, A. S., Horioka, C., \& Ferreira, A. A. (2010) Criatividade na velhice. Anais, XIV Congresso de Iniciação Científica da Universidade de Mogi das Cruzes. Recuperado em 08 julho, 2019, de: http://www.umc.br/_img/_diversos/pesquisa/pibic_pvic/XIV_congresso/ Arquivos/Alessandra\%20dos\%20Santos\%20Braga.pdf.

Campos, C. N., Santos, L. C., Moura, M. R., Aquino, J. M., \& Monteiro, E. L. M. (2012). Reinventando práticas de enfermagem na educação em saúde: teatro com idosos - Escola Anna Nery. Revista de Enfermagem, 16(3), 588-596. Recuperado em 08 julho, 2019, de: http://www.scielo.br/scielo.php?pid=S1414-81452012000300023\&script=sci_abstract\&tlng=pt.

Carlos, S. A., Jacques, M. G., Larratéa, S. V. \& Herédia, O. C. (1999). Identidade, aposentadoria e terceira idade. Estudos Interdisciplinares do Envelhecimento, 1, 77-89. Recuperado em 08 julho, 2019 de: https://seer.ufrgs.br/RevEnvelhecer/article/view/4653. 
Cordeiro, A. P. (2006). Oficinas de teatro da UNATI - Unesp de Marília: o lúdico como elemento estimulador dos processos de criação teatral da pessoa idosa. Educação em Revista, 7(1/2), 67-84. Recuperado em 08 julho, 2019, de: http://revistas.marilia.unesp.br/index.php/educacaoemrevista/article/view/608.

Cordeiro, A. P. (2015). Por mares de sonho e criação, de "fragmentos da vida" vamos "tecendo esperanças": a história das oficinas de teatro da Unati (Universidade Aberta à $3^{\mathrm{a}}$ idade). Unesp de Marília. In: Cordeiro, A. P., \& Dátilo, G. M. P. A. Envelhecimento humano: diferentes olhares, 69-94. São Paulo, SP: Cultura Acadêmica. Recuperado em 08 julho, 2019, de: https://www.marilia.unesp.br/Home/Publicacoes/envelhecimento-humano_ebook. pdf.

Cordeiro, F. R., Pinheiro, M. S., \& Correio, D. A. C. (2015). Sobre o envelhecimento, a mídia e a morte no contemporâneo. Estudos Interdisciplinares do Envelhecimento, 20(3), 975-990. Recuperado em 08 julho, 2019, de: https://seer.ufrgs.br/RevEnvelhecer/article/view/46243.

Correa, M. R. (2009). Cartografias do envelhecimento na contemporaneidade: velhice e terceira idade. São Paulo, SP: Cultura Acadêmica. Recuperado em 08 julho, 2019, de: http://books.scielo.org/id/4v5z9/pdf/correa-9788579830037.pdf.

Debert, G. G. (1999). Velhice e o curso da vida pós-moderno. Revista USP, 42, 70-83. Recuperado em 08 julho, 2019, de: http://www.revistas.usp.br/revusp/article/view/28456.

Debert, G. G. (2010). A dissolução da vida adulta e a juventude como valor. Horizontes antropológicos, 16(34), 49-70. Recuperado em 08 julho, 2019, de: http://www.scielo.br/scielo.php?script=sci_arttext\&pid=S0104-71832010000200003.

Featherstone, M., \& Werneck, A. (1995). Images of Aging - Cultural Representations of Later Life. London/New York: Routledge.

FNMI. (2012). Relatórios: I e II. Recife, PE: Secretaria da Mulher do Estado de Pernambuco.

Foucault, M. (1995). O sujeito e o poder. Apêndice da segunda edição. Michel Foucault entrevistado por Hubert L. Dreyfus e Paul Rabinow. In: Dreyfus, H., \& Rabinow, P. (Orgs.). Michel Foucault: uma trajetória filosófica, 251-278. Rio de Janeiro, RJ: Forense Universitária.

Gonçalves, C. D. (2015). Envelhecimento bem-sucedido, envelhecimento produtivo e envelhecimento ativo: reflexões. Estudos Interdisciplinares do Envelhecimento, 20(2), 645657. Recuperado em 08 julho, 2019, de: https://seer.ufrgs.br/RevEnvelhecer/article/view/49428.

Gusmão, N. M. M. A. (2001). Maturidade e a velhice: um olhar antropológico. In: Neri, A. L. (Org.). Desenvolvimento e envelhecimento: perspectivas biológicas, psicológicas e sociológicas, 113-139. Campinas, SP: Papirus.

Justo, J. S., Rozendo, A. S., \& Correa, M. R. (2010). O idoso como protagonista social. Revista SESC, 21(48), 39-53. Recuperado em 08 julho, 2019, de: http://www.sescsp.org.br/online/artigo/6403_o+idoso+como+protagonista+social\#/tagcloud=lista.

Laroque, M., Affeldt, Â., Gheno, B., Dias, D., \& Santana, M. G. (2013). A criatividade na terceira idade. Revista Contexto \& Saúde, 6(11), 7-14. Recuperado em 08 julho, 2019, de: https://www.revistas.unijui.edu.br/index.php/contextoesaude/article/view/1387. 
Martins, J. B. (1996). Observação participante: uma abordagem metodológica para a psicologia escolar. Semina: Ciências Sociais e Humanas, 17(3), 266-273. Recuperado em 08 julho, 2019, de: http://www.uel.br/revistas/uel/index.php/seminasoc/article/view/9472/8263.

Miguel, D. (2012) A prática teatral no envelhecimento: um caminho para o autoconhecimento, para a autonomia e para a inclusão social. A terceira idade, 55, 7-18. Recuperado em 08 julho, 2019, de: https://www.sescsp.org.br/online/artigo/6563_ a+pratica+teatral+no+envelhecimento+um+caminho+para+o+autoconhecimento+para+a+aut onomia+e+para+a+inclusao+social.

Monteiro, P. P. (2005). Somos velhos porque o tempo não para. In: Arcuri, B., Côrte, B., \& Mercadante, E. F. (Orgs.). Velhice e envelhecimento - complex(idade, 57-82. São Paulo, SP: Vetor. Recuperado em 08 julho, 2019, de: https://portaldoenvelhecimento.com/revistanova/index.php/revistaportal/article/view/74/74.

Moreira, V., \& Nogueira, F. N. N. (2008). Do indesejável ao inevitável: a experiência vivida do estigma de envelhecer na contemporaneidade. Psicologia USP, 19(1), 59-79. Recuperado em 08 julho, 2019, de: http://www.redalyc.org/articulo.oa?id=305123726009.

Motta, A. B. (2002). Visão antropológica do envelhecimento. In: Freitas, E. V., \& Py, L. (Orgs.). Tratado de geriatria e gerontologia, 78-82. Rio de Janeiro, RJ: Guanabara Koogan.

Neri, A. L. (2006). O Legado de Paul B. Baltes à psicologia do desenvolvimento e do envelhecimento. Temas em Psicologia, 14(1), 17-34. Recuperado em 08 julho, 2019, de: http://pepsic.bvsalud.org/pdf/tp/v14n1/v14n1a05.pdf.

Neri, A. L., \& Freire, S. A. (2000). E por falar em boa velhice. Campinas, SP: Papirus.

Nietzsche, F. (1996). A gaia ciência. Lisboa, Portugal: Guimarães.

OPAS, OMS. (2005). Envelhecimento ativo: uma política de saúde. Brasília, DF: Organização Pan-Americana da Saúde/Organização Mundial de Saúde. Recuperado em 08 julho, 2019, de: http://bvsms.saude.gov.br/bvs/publicacoes/envelhecimento_ativo.pdf.

Papalia, D. E., Olds, S. W., \& Feldman, R. D. (2006). Desenvolvimento humano. Porto Alegre, RS: Artmed.

Pavón, M., \& Dottori, K. (2015). Creatividad en la vida cotidiana. Revista KairósGerontologia, 18(21), 137-153. Recuperado em 08 julho, 2019, de: https://revistas.pucsp.br/kairos/article/download/29458/20556.

Relatório Mundial sobre Envelhecimento e Saúde. (2015). Centro Internacional de Longevidade do Brasil. Envelhecimento ativo: um marco político em resposta à revolução da longevidade. Rio de Janeiro, RJ: ILC, 2015. Recuperado em 08 julho, 2019, de: http://ilcbrazil.org/wp-content/uploads/2016/02/Envelhecimento-Ativo-Um-MarcoPol\%C3\%ADtico-ILC-Brasil_web.pdf.

Silva, L. J., Vianna, L. G., \& Bezerra, A. J. C. (2013). Reflexões sobre o envelhecimento e sobre processos criativos na maturidade a partir dos autorretratos de Rembrandt. Revista Kairós-Gerontologia, 16(2), 77-91. Recuperado em 08 julho, 2019, de: https://revistas.pucsp.br/kairos/article/view/17633.

Silva, L. R. F. (2008). Da velhice à terceira idade: o percurso histórico das identidades atreladas ao processo de envelhecimento. História, Ciências, Saúde-Manguinhos, 15(1), 155168. Recuperado em 08 julho, 2019, de: http://www.scielo.br/scielo.php?script=sci_arttext\&pid=S0104-59702008000100009. 
Souza, A. A. F., \& Wechsler, S. M. (2013). Inteligência e criatividade maturidade e velhice. Psicologia Reflexiva e Crítica, 26(4), 643-653. Recuperado em 08 julho, 2019, de: http://www.scielo.br/scielo.php?script=sci_arttext\&pid=S0102-79722013000400004.

Teixeira, A. S. M. O., Santiago, F. X. S. M., Cintra, D. F., Jr., \& Martins, J. C. O. (2015). Reflexões acerca do estigma do envelhecer na contemporaneidade. Estudos Interdisciplinares do Envelhecimento, 20(2), 503-515. Recuperado em 08 julho, 2019, de: https://seer.ufrgs.br/RevEnvelhecer/article/view/45346.

Tótora, S. (2015). Velhice: uma estética da existência. São Paulo, SP: EDUC: FAPESP.

Tótora, S. (2017). Envelhecimento ativo: proveniências e modulação da subjetividade. Revista Kairós-Gerontologia, 20(1), 239-258. Recuperado em 08 julho, 2019, de: https://revistas.pucsp.br/index.php/kairos/article/view/33496.

Valdès, S. E. C. (2012). ¿Es la vejez lo que se dice de ella? Revista Temática KairósGerontologia, 15(4), 11-22. Recuperado em 08 julho, 2019, de: https://revistas.pucsp.br/index.php/kairos/article/view/17034.

Veloz, M. C. T., Schulze, C. M., \& Camargo, B. V. (1999). Representações sociais do envelhecimento. Psicologia, reflexões e críticas, 12(2), 479-501. Recuperado em 08 julho, 2019, de: http://www.scielo.br/scielo.php?script=sci_arttext\&pid=S0102-79721999000200015.

Veras, R. P. (2001). Desafios e conquistas advindas da longevidade da população: o setor de saúde e as suas necessárias transformações. In: Veras, R. P. (Org.). Velhice numa perspectiva de envelhecimento saudável, 11-32. Rio de Janeiro, RJ: UERJ.

Zuben, N. A. V. (2003). Envelhecimento: metamorfose de sentido sob o significado da finitude. In: Neri, A. L. (Org.) Maturidade e velhice - trajetórias individuais e socioculturais, 151-182. Campinas, SP: Papirus.

Recebido em 04/02/2019

Aceito em 30/06/2019

Cinthia Lucia de Oliveira Siqueira - Fonoaudióloga, Universidade de São Paulo. Especialista em Linguagem. Mestre em Educação, Universidade Metodista de Piracicaba. Doutora em Psicologia, Programa de Pós-Graduação em Psicologia Social, da Universidade Estadual Paulistas Júlio de Mesquita Filho, UNESP/Assis.

ORCID iD: https://orcid.org/0000-0002-7047-6923

E mail: cinthialucia2702@gmail.com 
João Batista Martins - Psicólogo. Mestre em Antropologia, Universidade Federal de Santa Catarina. Doutor em Educação, Universidade Federal de São Carlos. Pós-Doutor em Psicologia, Universidade de São Paulo. Docente do Programa de Pós-Graduação em Psicologia da UNESP/Assis.

E-mail: jbmartin@sercomtel.com.br 